\title{
Escolha de alternativas para economia de água em edificações residenciais de Brasília, DF
}

\author{
VIANNA, Jorge Thiago Duarte da Silva ${ }^{1}$ \\ SOUZA, Marco Antonio Almeida ${ }^{2}$
}

1Exército Brasileiro, Brasília, Brasil. jorgethiago@globo.com 2 PTARH/UnB - Pós Graduação em Tecnologia ambiental e recursos hídricos, Brasil. marcantoniosouza@gmail.com
\end{abstract}

\begin{abstract}
Resumo
O crescimento populacional, o uso indiscriminado de água e a poluição de alguns mananciais vêm produzindo crises de abastecimento de água. Este é o caso de Brasília, para o qual este trabalho analisou o emprego dos métodos de conservação de água em edificações residenciais. Nessa análise, foi selecionado um imóvel padrão e foram estudadas as diversas combinações das alternativas possíveis. Devido ao grande número de alternativas, foi realizado um processo de triagem para se obter um conjunto menor de alternativas viáveis. As alternativas de conservação de água em edificações residenciais que permaneceram na análise foram as seguintes: reúso de água cinza segregada, economizadores, utilização de água da chuva e medição individual. Foram definidos os critérios de medida da performance dessas alternativas a partir de consulta feita a diversos especialistas. As alternativas selecionadas tiveram então suas performances em cada critério calculadas, formando uma matriz de consequências. A essa matriz foram aplicados os métodos multicritério e multiobjetivo TOPSIS e ELECTRE III III, para hierarquizar essas alternativas. O resultado da execução desses métodos mostrou que o uso de equipamentos economizadores de água ocupou o primeiro lugar no ranking das alternativas de conservação de água em prédios residenciais, para o caso estudado de Brasília.
\end{abstract}

Palavras-Chave: conservação de água; predial; multicritério; Brasília

\begin{abstract}
Population growth, the indiscriminate use of water and the pollution of some water sources have led to water supply crises. This is the case of Brasilia, for which this work analyzed the use of water conservation methods in residential buildings. In this analysis, a standard property was selected and the different combinations of possible alternatives were studied. Due to the large number of alternatives, a screening process was carried out to obtain a smaller set of viable alternatives. The alternatives of water conservation in residential buildings that remained in the analysis were as follows: reuse of segregated gray water, economizers, use of rainwater and individual measurement. The criteria for measuring the performance of these alternatives were defined based on consultation with several specialists. The selected alternatives then had their performances in each calculated criterion, forming an array of consequences. To this matrix, the multicriteria and multiobjective methods TOPSIS and ELECTRE III III were applied to hierarchize these alternatives. The result of the execution of these methods showed that the use of water saving equipment occupied the first place in the ranking of the alternatives of water conservation in residential buildings, for the case studied in Brasilia.
\end{abstract}

Key-Words: water conservation; multicriteria; Brasília 


\section{Introdução}

Com o passar dos anos, ocorreu um aumento expressivo da demanda mundial por água, influenciado por questões climáticas, pelo crescimento populacional, pelo uso indiscriminado de água e pela poluição de alguns mananciais. Isso vem produzindo crises de abastecimento de água e limitando as atividades econômicas. No cenário brasileiro, alerta-se para um possível aumento da demanda de água de $28 \%$ até 2025 (Atlas Brasil, 2010), enquanto a projeção do crescimento populacional é de cerca de 10\% (IBGE, 2016).

Nesse contexto, a presente pesquisa tomou como estudo de caso Brasília, no Distrito Federal, um espaço altamente urbanizado, com altos consumos de água e inserido numa região de nascentes de água. No ano 2000, o Distrito Federal apresentava disponibilidade hídrica inferior ao recomendado para um abastecimento normal, alertando para uma situação difícil. Já nos dias atuais, o Distrito Federal ocupa o primeiro lugar do Brasil em estresse hídrico (Rebouças, 2002; IBGE, 2016), caracterizando escassez crônica de água.

Com o aumento na demanda por água e escassez na oferta, situação típica dos grandes centros urbanos, surgiu a necessidade de conservar a água. Para tentar suprir essa necessidade, a atenção voltou-se para as regiões de maior consumo per capita do Distrito Federal: Plano Piloto e Lago Sul (CAESB, 2012). Como os imóveis no Lago Sul caracterizam-se por residências unifamiliares, o foco deslocou-se para aos grandes consumidores multifamiliares, que representam, isoladamente, as parcelas de maior consumo de Brasília. Esses locais destacam-se pelo alto consumo, caracterizado numa única fatura de água, visto que não apresentam medidores individualizados, concentrando em um único medidor o consumo de água de várias unidades habitacionais.

Diante do exposto, a abordagem deste trabalho consistiu na escolha de um estudo de caso composto por um imóvel multifamiliar vertical típico de Brasília, onde foram analisadas algumas alternativas para conservação de água. Tais alternativas foram comparadas mediante o emprego dos métodos multiobjetivo e multicritério e hierarquizadas por meio de seus respectivos desempenhos. Com essa prioridade estabelecida foi avaliada a utilização de cada alternativa.

Os trabalhos anteriores não abordaram a temática sob o ângulo da presente pesquisa. Sant'Ana (2011) se deteve nos estudos de viabilidade econômica. Santos et al. (2006) utilizaram multicritério com enfoque em uma escala macro baseada no crescimento de uma cidade. Lobato (2005) escolheu para estudo de caso uma edificação qualquer, projetando a economia obtida para o nível de cidade.

Esse trabalho estudou o abastecimento de água na capital do país, com histórico recente de crise hídrica, com adoção de racionamento e com o maior crescimento populacional do Brasil. Por ser uma cidade planejada, foi possível utilizar dados de uma tipologia padrão da cidade, podendo-se projetar os resultados para toda a cidade com baixo grau de erro. Além disso, este trabalho criou e utilizou alternativas de referência para comparação, tais quais não adotar nenhuma alternativa, onerar a conta devido a medidas de contingenciamento, e a implantação de reúso de água por meio de tubos de queda de lavanderia (possibilidade comum em prédios antigos). A metodologia adotada neste trabalho parte da hipótese de que é importante para a sociedade a adoção de um método de análise de decisão que atenda concomitantemente os objetivos econômicos, ambientais, sociais, técnicos e de qualidade de água, além de incluir a visão dos diferentes atores intervenientes no processo decisório.

\section{Estratégias para conservação de água}

A conservação de água é definida por Hespanhol e Gonçalves (2004) como o conjunto de práticas e iniciativas técnicas e tecnológicas para reduzir o uso da água, atuando tanto na demanda quanto na oferta de água. Ela prevê o uso da água de forma racional, sustentável, e incentiva o uso de fontes alternativas. 
Entre as diversas formas de conservação de água, cita-se a medição individual, os economizadores de água, o uso de água da chuva e o reúso de água (com esgoto não segregado ou com água cinza).

Antes de estudar sobre cada método, faz-se necessário conhecer o perfil de consumo de água. Em geral, hábitos, cultura regional, localização geográfica, tradições, número de moradores, tempo de permanência, clima, renda e valor da tarifa de água costumam influenciar tais resultados (Hafner, 2007). Entre os estudos nacionais em residências, destacam-se os de Barreto (1990), Rocha (1999), Mieli (2001), Lobato (2005), Sant'Ana (2012) e Sant'Ana (2013).

A Tabela 1 aponta os dados de uma pesquisa para os consumos referentes aos usos nas áreas comuns de uma edificação. Durante a estação chuvosa, a irrigação restringe-se apenas a vasos com plantas ornamentais com 0,002 L/m²/dia (Sant'Ana, 2013).

Tabela 1: Consumo da área comum

\begin{tabular}{cc}
\hline Utilização & Consumo (\%) \\
\hline Irrigação de Jardins & 1,05 \\
Limpeza Condominial & 3,15 \\
\hline \multicolumn{2}{c}{ Fonte: Chain et al. (1999) }
\end{tabular}

Uma pesquisa foi realizada no Plano Piloto por Sant'Ana et al. (2013), cujos resultados são mostrados na Figura 1, mostrando que os chuveiros e as máquinas de lavar roupa são os equipamentos com maior parcela de uso de água. Os chuveiros têm seu consumo diretamente relacionado ao modo como as pessoas utilizam o equipamento (uma questão cultural), tal como duração do banho, fechamento durante o processo de ensaboar, etc. Por outro lado, equipamentos de redução de vazão instalados no chuveiro colaboram significativamente com essa redução. Em segundo lugar têm-se as máquinas de lavar roupa, onde existe uma questão cultural relacionada à utilização da máquina com carga plena de roupas a fim de otimizar o uso da água e a outra relacionada a eficiência do equipamento, intrínseco do fabricante, principalmente na relação entre o volume de água gasto e a quantidade de roupa lavada.

Iniciando com a prática de individualizar as medições de consumo de água residencial, por ser um requisito legal, tem-se uma redução de até $22 \%$ no volume de água consumido (Silva, 2010). Essa economia, apesar de controversa (devido ao baixo número de estudos), é consequência do melhor gerenciamento do uso de água pelo cidadão e não de uma intervenção sobre a quantidade efetivamente. Para a implantação da medição individualizada nos prédios antigos, é comum adotar-se um sistema de medição por telemetria. Esse sistema possui a desvantagem de exigir manutenção mensal estimada em $\mathrm{R} \$ 4,00$ (Techmetria, 2016).

Figura 1: Uso da água em edificações multifamiliares

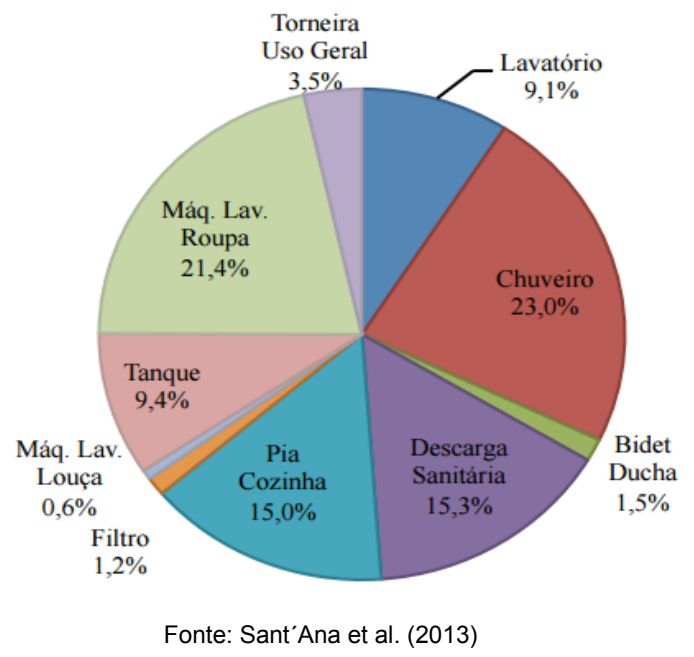


Os economizadores de água são, em geral, aparelhos que reduzem a vazão ou limitam o tempo de acionamento do dispositivo com fechamento automático do mesmo. O desempenho de cada um é exibido na Tabela 2.

Em relação ao aproveitamento da água de chuva, é interessante notar que a cidade de Brasília se insere numa região com períodos bem caracterizados de chuva e seca, conforme mostrado na Figura 2, assim como Belo Horizonte, Goiânia e Palmas, todas com precipitação anual similar, variando de 1600 a $1800 \mathrm{~mm}$.

Se se deseja captar a água de chuva, recomenda-se que seja feito o descarte dos $2 \mathrm{~mm}$ iniciais de chuva na área de coleta, com o intuito de obter água com menos poluentes (ABNT, 2007). Murça (2011) afirma que esse descarte inicial conseguiu diminuir a turbidez em $75 \%$ e a DBO em $50 \%$ quando aplicado no PAMA-GL (Parque de Material Aeronáutico do Galeão - RJ).

Tabela 2: Economia gerada pelos aparelhos economizadores de água

\begin{tabular}{cccc}
\hline Local & Aparelhos Indicados & $\begin{array}{c}\text { Economia } \\
\text { (\%) }\end{array}$ & $\begin{array}{c}\text { Tempo retorno } \\
\text { (meses) }\end{array}$ \\
\hline Chuveiro & Registro regulador de vazão & 20 & 6 \\
Lavatório & Registro regulador de vazão & 20 & 5 \\
& Arejador para bica ou torneira & 20 & 5 \\
Bacia & Torneira automática & 25 & 8 \\
sanitária & Bacia com caixa acoplada 6L & 50 & 6 \\
Pia de & Bacia com válvula duplo acionamento & 20 & 8 \\
cozinha & Arejador para bica ou torneira & 20 & 5 \\
& Registro regulador de vazão & 20 & 5 \\
\hline
\end{tabular}

Figura 2: Precipitação média mensal em capitais brasileiras com estiagem

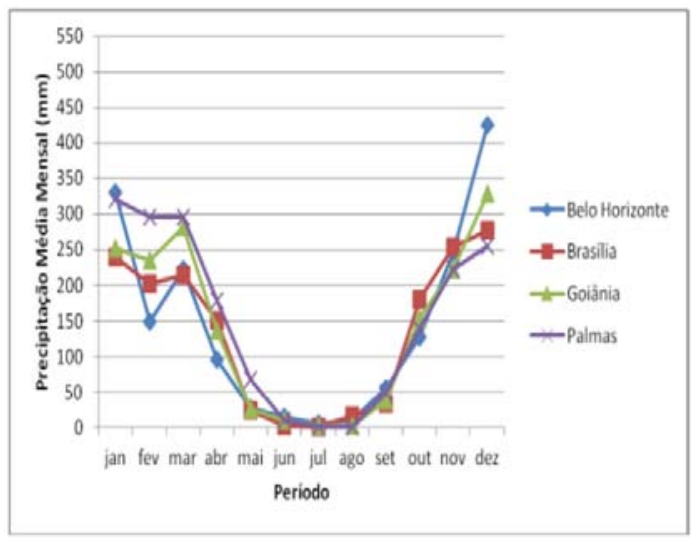

Fonte: Zardini (2014)

Apesar do custo de implementação de um sistema de captação e aproveitamento de água pluvial ser reduzido e possuir grandes vantagens, a construção de reservatórios atinge $55 \%$ do investimento total, tornando-se o grande limitador pela análise econômica (Campos, 2004). Com esse alto custo do reservatório, faz-se necessário um estudo complexo visando obter seu volume ideal. Um bom dimensionamento deve produzir um reservatório que não fique um longo período ocioso, nem pode provocar o desperdício de água pluvial. 
Já o método de uso racional da água mais comum empregado na maioria dos países, no nível residencial, é o reúso de água com água cinza, pois elas possuem baixo teor de poluentes e a sua produção é suficiente para os usos normais na própria residência. Nesse caso, a água é coletada, tratada e armazenada em reservatórios para uso posterior. O método de segregação do esgoto consiste em separar a água negra da cinza, na fonte, utilizando tubulações distintas. Dessa forma, a fração referente à água cinza poderá ser utilizada sem qualquer contaminação pelas águas negras. As utilizações mais comuns da água de reúso são irrigação paisagística, lavagem de logradouros públicos e veículos, desobstrução de tubulações, na construção civil, em edificações, no combate a incêndios e dentro da área urbana (BRASIL, 2005).

Para o projeto de reúso predial de água com esgoto segregado, ao serem comparadas a água cinza com as águas negras, verifica-se que o fluxo horário é diferente. Com isso, para atender às vazões da demanda nas bacias sanitárias durante todo o dia, é necessário armazenar água de um dia para o outro.

As características de qualidade químicas e biológicas da água cinza variam bastante conforme a fonte e estão descritas na Tabela 3. A partir da comparação dessas características com as legislações internacionais para o reúso de água em bacias sanitárias, destacando-se a Legislação Alemã como a menos restritiva, cujo o limite de DBO é de $20 \mathrm{mg} / \mathrm{L}$ e Coliformes Totais de 100 UFC/100mL (Lazarova et al., 2003), chega-se à conclusão de que há necessidade de tratamento da água cinza para o seu aproveitamento.

Tabela 3: Qualidade da água de reúso

\begin{tabular}{cccccc}
\hline $\begin{array}{c}\text { Equipam } \\
\text { ento }\end{array}$ & $\begin{array}{c}\mathrm{DQO} \\
(\mathrm{mg} / \mathrm{L})\end{array}$ & $\begin{array}{c}\mathrm{DBO} \\
(\mathrm{mg} / \mathrm{L})\end{array}$ & $\begin{array}{c}\mathrm{SST} \\
(\mathrm{mg} / \mathrm{L})\end{array}$ & $\begin{array}{c}\mathrm{CT} \\
(\mathrm{NMP} / 100 \mathrm{~mL})\end{array}$ & $\begin{array}{c}\mathrm{CF} \\
(\mathrm{NMP} / 100 \mathrm{~mL})\end{array}$ \\
\hline $\begin{array}{c}\text { Chuveiro } \\
\text { Lavatório }\end{array}$ & 582 & 164 & 106 & $3,9 \times 104$ & $2,5 \times 103$ \\
$\begin{array}{c}\text { Máquina } \\
\text { de lavar }\end{array}$ & 521 & 624 & 206 & $8,9 \times 105$ & $1,5 \times 103$ \\
$\begin{array}{c}\text { Roupa } \\
\text { Tanque }\end{array}$ & 1672 & 570 & 221 & $2,06 \times 102$ & $1,0 \times 103$ \\
\hline \multicolumn{5}{c}{ Fonte: Adaptado de Bazzarela $(2005)$} &
\end{tabular}

Outro aspecto a ser analisado, é o tempo de permanência da água cinza nos reservatórios. Dixon \& Butler (1999) apud Rapoport (2004) observaram que, num tempo de estocagem de 24 horas, a qualidade da água melhora devido à rápida sedimentação. Entretanto, o aumento desse tempo para 48 horas leva à diminuição do oxigênio dissolvido e consequentes problemas de odor. Nirenberg (2010) alerta que os reservatórios devem possuir uma ventilação com o propósito de não acumular gases.

\section{Métodos multicritérios}

Os métodos multiobjetivos têm sido adotados como ferramentas para o sistema de apoio a decisão, o qual caracteriza-se pela necessidade de obter respostas a determinadas questões (Roy, 1985), ou ainda, tomar uma decisão diante de um problema que tenha mais de uma solução (de Paula, 2013). Trata-se, portanto, de um conjunto de ferramentas que permite ao tomador da decisão um avanço entre os diversos pontos de vistas (Vincke,1992).

Desde 1973, esses métodos vêm sendo utilizados para solução de problemas ambientais. O exemplo clássico é o método custo-efetividade utilizado por Popovich com o objetivo de selecionar alternativa para manejo dos resíduos sólidos no Arizona (Souza \& Forster, 1996).

A abordagem tradicional de analise técnico-econômica tem cedido lugar a uma análise mais ampla, com diversos objetivos. Essa nova análise é mais complexa, porém tem maior sustentação de argumentação, pois se aproxima mais dos problemas e decisões enfrentados no dia-a-dia (Braga et al., 
1998).

Existem diversas técnicas multiobjetivo e multicritério. A escolha de cada uma dependerá de fatores como informações, natureza do problema, condicionantes, etc

Nesta pesquisa, serão abordados os métodos ELECTRE III III e TOPSIS. Foram selecionados dois métodos com o propósito de buscar o ótimo de Pareto independente da robustez do método, diminuindo assim os erros durante o procedimento de hierarquização, e por estarem esses métodos enquadrados entre os métodos que trabalham a problemática.

Os dois métodos foram selecionados entre outros devido a sua simplicidade, facilidade de uso, disponibilidade de software e transparência. Em relação ao ELECTRE III III, há o diferencial que ele permite eliminar alternativas e ordená-las. Em relação ao TOPSIS, há um aumento crescente de artigos publicado desde 2010 utilizando essa técnica.

\section{Materiais e Método}

\subsection{Definição da tipologia}

Esse trabalho tomou por base a tipologia do edifício mais comum existente em Brasília, que tem com as seguintes características:

a) 48 apartamentos;

b) Área de telhado de $1129 \mathrm{~m}^{2}$;

c) 4 caixas de água, cada uma com $23 \mathrm{~m}^{3}$;

d) Dois reservatórios inferiores com $30 \mathrm{~m}^{3}$ cada;

e) Cada apartamento com área de $115 \mathrm{~m}^{2}$, sendo composto por uma suíte, dois quartos, um banheiro social, uma cozinha, área de serviço e um banheiro de empregada;

f) Uma vaga na garagem por apartamento;

g) Consumo médio de $151 \mathrm{~L} / \mathrm{hab} /$ dia.

\subsection{Estabelecimento de alternativas de referência}

Para melhor comparar as alternativas, foram estabelecidas quatro alternativas de referência: não adotar qualquer medida (Alternativa A1), adotar apenas componentes economizadores (Alternativa A2) e o reúso da água de máquinas de lavar roupa (Alternativa A3 e A4). Essas alternativas serviram de base para referenciar a sensibilidade da classificação imposta pelo método.

A primeira alternativa de referência trata da situação atual de Brasília. Nela incorporou-se ao custo de operação a tarifa de contingenciamento $(40 \%)$ e atribuiu-se ao desperdício todo o volume de água cinza que é passível de reúso. Para a demanda de água predial foi atribuído o valor referente ao consumo da bacia sanitária, jardim e lavagem comum (por tratarem-se do máximo valor a ser economizado).

A segunda alternativa de referência teve como objetivo comparar a adição das medidas incrementais às medidas de redução. Para tanto, foi considerado apenas o custo de implantação, manutenção dos economizadores e sua economia gerada ao sistema.

A terceira e quarta alternativa de referência foram inseridas devido à facilidade, mesmo em instalações antigas, de se conseguir acesso à tubulação oriunda da área de serviço (máquina de lavar roupa e tanque). Em geral, essa tubulação já é separada do restante das instalações e está visível no subsolo dos blocos. Com isso, a probabilidade de instalação do sistema de reúso aumenta e diminuem 
significativamente os custos com obras civis.

\subsection{Objetivos e critérios para a análise de decisão}

A metodologia de pesquisa incluiu o estabelecimento e definição dos objetivos e critérios de avaliação das alternativas, assim como seus respectivos pesos, que ão mostrados na Tabela 4, para comparação de medidas de conservação de água. Esses dados foram obtidos através da consulta a 178 especialistas e gestores (doutores, mestres e gestores) das mais diversas instituições com o uso da ferramenta "LimeSurvey". Esse processo constou de duas fases: na primeira, houve a colheita de critérios dos participantes, e na segunda, tais critérios foram pontuados de acordo com a importância pelos participantes. Os outliers foram retirados e a média ponderada foi calculada para cada um deles, estabelecendo pesos para cada critério e objetivo.

Tabela 4: Critérios de comparação das alternativas

\begin{tabular}{|c|c|c|c|}
\hline Critério de julgamento & Unidade & Peso & $\begin{array}{l}\text { Quando é } \\
\text { melhor? }\end{array}$ \\
\hline OBJETIVO ECONÔMICO & & $\underline{2,02}$ & \\
\hline Valor presente líquido & $\mathrm{R} \$$ & $\overline{0,444}$ & Maior \\
\hline Custo de implantação & $\mathrm{R} \$$ & 0,554 & Menor \\
\hline Custo de operação & $\mathrm{R} \$$ & 0,552 & Menor \\
\hline $\begin{array}{l}\text { Tempo de retorno } \\
\text { OBJETIVO DE QUALIDADE DE ÁGUA }\end{array}$ & Meses & $\begin{array}{c}0,468 \\
2,08\end{array}$ & Menor \\
\hline DBO - Demanda Bioquímica de Oxigênio & $\mathrm{mg} / \mathrm{L}$ & 0,657 & Menor \\
\hline SST - Sólidos Suspensos Totais & $\mathrm{mg} / \mathrm{L}$ & 0,686 & Menor \\
\hline CF - Coliformes Fecais & NMP/100mL & 0,736 & Menor \\
\hline OBJETIVO AMBIENTAL & & $\underline{2,11}$ & \\
\hline Volume de água reduzido do consumo final & L & $\overline{0,632}$ & Maior \\
\hline $\begin{array}{c}\text { Volume de água a ser complementado por fornecimento } \\
\text { externo (pela CAESB) }\end{array}$ & L & 0,479 & Menor \\
\hline Volume de água desperdiçado & L & 0,524 & Menor \\
\hline $\begin{array}{l}\text { Quantidade de lodo produzido } \\
\text { OBJETIVO SOCIAL }\end{array}$ & Kg/ano & $\begin{array}{c}0,473 \\
1,86\end{array}$ & Menor \\
\hline Risco a saúde (método de Beta-Poisson) & Sem unidade & 0,722 & Maior \\
\hline Risco anual de falta de água & $\%$ & 0,604 & Menor \\
\hline Interferência ao morador & $\begin{array}{l}\text { Número inteiro (de } 0 \text { a } \\
10 \text { ) }\end{array}$ & 0,533 & Menor \\
\hline OBJETIVO TÉCNICO & & $\underline{1,96}$ & \\
\hline Consumo de energia & $\mathrm{KWh} / \mathrm{m}^{3}$ & $\overline{0,662}$ & Menor \\
\hline Área ocupada pelo sistema & $\mathrm{m}^{2}$ & 0,615 & Menor \\
\hline Complexidade do sistema & $\begin{array}{l}\text { Número inteiro (de } 0 \text { a } \\
10 \text { ) }\end{array}$ & 0,681 & Menor \\
\hline
\end{tabular}

O risco à saúde foi determinado através da fórmula de Beta-Poisson sobre a possibilidade de ingestão de água contaminada tendo como parâmetro os limites da EPA.

O método de Beta-Poisson proposto por Watercasa (2004) foi selecionado pois este considera que a probabilidade de infecção varia de acordo com a população, enquanto o modelo exponencial pressupõe que os microrganismos estão distribuídos de maneira aleatória e com a mesma probabilidade de contaminação. Além do que, os parâmetros desse método são bem definidos para a Escherichia Coli, com alfa igual a 0,1705 e beta igual 1,61x 106 .

A EPA (1992) definiu que um indivíduo exposto a uma contaminação menor que 0,0001 (PP) ao ano não estaria sob risco. Assim, é possível relacionar a quantidade de água contaminada ingerida, o número de dias de ingestão e a população de coliforme presente.

\subsection{Regras e normas utilizadas para a geração das alternativas técnicas de conservação predial de água \\ Foram definidas as alternativas compostas por medidas de redução e por medidas incrementais.}


Contudo, não seria suficiente afirmar que uma única medida satisfaria as necessidades de conservação e desempenho no modelo de geração de alternativas adotado. Por isso, foi necessário fazer as combinações entre as diversas possibilidades de medidas de conservação predial de água.

Entre as medidas que geram redução, foram consideradas as seguintes:

a) Medição individual;

b) Equipamentos economizadores.

Entre as medidas incrementais, foram consideradas as seguintes:

a) Aproveitamento de água de chuva;

b) Reúso de água com utilização de água cinza.

Para o sistema de reúso de água, considerou-se apenas o tipo de reúso de água com o esgoto segregado, e assim mesmo, no sistema com a água cinza clara, na tentativa de simplificar o sistema e sua operação. $O$ sistema não segregado apresenta maior concentração de partículas em suspensão e maior carga orgânica. Dessa forma, o uso não segregado iria requerer um tratamento mais complexo. Além de que, no balanço hídrico entre as fontes e consumos prediais, haveria um excedente de água de reúso, obrigando o seu descarte.

Para todas as alternativas compostas por medidas incrementais, precisou-se antes definir quais seriam as demandas de água a considerar, cujas opções foram as seguintes:
a) Bacias sanitárias;
b) Irrigação de jardins;
c) Lavagem de pisos;

Com isso, cada medida de redução iria se desdobrar em combinações (de 3, 2 ou apenas 1 opção de demanda), perfazendo um total de 7 alternativas.

Para a concepção do reúso de água com a água cinza clara, além da definição das demandas, há a necessidade de definir as ofertas (que servirão de fonte de água), cujas opções foram:

a) Tanque de lavar roupa;

b) Lavatório do banheiro;

c) Chuveiro;

d) Máquina de lavar roupa.

No estudo de caso, as instalações hidrossanitárias serão novas, com base nas necessidades de conservação de água. Portanto, os hábitos de projetos tradicionais para esgoto poderão não ser feitos, sem contrariar as normas vigentes. Exemplo disso é rotineira ligação do ramal do esgoto do chuveiro com o lavatório numa caixa sifonada única. Essa separação viabiliza os itens "b" e "c", de acordo com a necessidade.

Contudo, ainda existirão as combinações oriundas dessas ofertas (de 4, 3, 2 ou apenas 1 opção de fonte de água), ficando um total de 15 alternativas.

Através de combinação das demandas e ofertas, teve-se um total de 105 alternativas, tendo sido necessário criar um método que pudesse realizar a triagem das opções no intuito de diminuir o número de alternativas viáveis. 
As alternativas finais foram geradas a partir de duas combinações básicas: a adoção da medida de redução que obteve o melhor desempenho econômico individualmente e uma medida incremental.

Em todos os usos finais de aparelhos, serão utilizados dados médios de consumo, com o propósito de distribuir as possíveis singularidades de cada local e fonte, tentando minimizar os desvios padrões em relação à Brasília.

Para realizar a triagem das alternativas, foi necessário definir alguns parâmetros, tal como a vida útil dos sistemas adotados nas diversas alternativas. A vida útil é o tempo durante o qual um equipamento funciona de forma eficiente e produtiva. A maioria dos equipamentos envolvidos nos sistemas prediais (por exemplo, bombas hidráulicas) tem a vidas útil próxima a 10 anos. Outros sistemas menos complexos, como as tubulações, têm vida útil de 20 anos (ABNT, 2013). Já a edificação tem estimativa de até 60 anos. De posse desses valores de vida útil, foi adotado o tempo de retorno do investimento ideal para 30 anos.

Outro parâmetro considerado foi a preferência por escolhas independentes do sistema da rede de água potável, ou seja, que não necessitam de consumo adicional de água potável da rede da concessionária.

Para fins de comparação, incluiu-se a alternativa de não conservar água, ou seja, não tomar nenhuma medida e consequentemente não afetar custos e outros parâmetros. Além desta, surgiu a necessidade de incluir a alternativa que trata da coleta da água cinza oriundas da máquina de lavar roupa e tanque, com a finalidade de reúso para lavagem de piso, carro e irrigação de jardim. Essa necessidade vem do conceito de que a maioria das edificações estudadas tem as tubulações da área de serviço numa única prumada e com fácil acesso pelo subsolo. Assim, os custos de reforma são mínimos e o processo de instalação torna-se rápido, por não haver nenhuma demanda interna aos apartamentos.

\subsection{Descrição e detalhamento da alternativa de implantação de aparelhos economizadores}

Cada aparelho de cada apartamento foi analisado e teve considerada a implantação de um componente economizador (ECO). O custo desses aparelhos na edificação foi considerado como a soma dos custos em um apartamento multiplicado pelo número de apartamentos. Os dados inerentes a custo foram destacados na Tabela 5:

Tabela 5: Custo dos economizadores

\begin{tabular}{cccc}
\hline Nome & $\begin{array}{c}\text { Valor } \\
\text { Unitário } \\
(\mathbf{R} \$ \mathbf{)}\end{array}$ & $\begin{array}{c}\text { Qtd por } \\
\text { apartamento }\end{array}$ & $\begin{array}{c}\text { Preço por } \\
\text { apartamento } \\
\text { (R\$) }\end{array}$ \\
\hline $\begin{array}{c}\text { Válvula } \\
\text { descarga } \\
\text { DUO }\end{array}$ & 299,90 & 3,00 & 899,70 \\
$\begin{array}{c}\text { Restritor } \\
\text { vazão } \\
\text { chuveiro }\end{array}$ & 14,00 & 3,00 & 42,00 \\
$\begin{array}{c}\text { Arejador } \\
\text { torneira }\end{array}$ & 12,40 & 3,00 & 37,20 \\
lavatório & & & \\
$\begin{array}{c}\text { Arejador } \\
\text { torneira } \\
\text { cozinha }\end{array}$ & 32,90 & 1,00 & 32,90 \\
& & & \\
& & Subtotal & $1.011,80$ \\
Qtd aptos & \\
Total & $48.566,40$ \\
\hline
\end{tabular}

Não foi encontrada nenhuma fonte de dados de custos de manutenção. Com isso, foi adotado que os 
elementos economizadores têm sua manutenção condicionada à substituição de peças complementares, tais como reparos, carrapetas, etc. Os custos foram estimados em $\mathrm{R} \$ 7,18$ por ano.

\subsection{Descrição e detalhamento da alternativa de implantação de medição individual}

A economia média de consumo esperada nesse sistema de medição individual é de $22 \%$, o que foi adotado neste estudo.

Estimou-se para este trabalho um custo de $\mathrm{R} \$ 500,00$, incluindo as obras civis, para cada prumada de alimentação existente em um apartamento - os apartamentos atuais possuem uma única prumada, mas os antigos chegam a ter cinco.

\subsection{Detalhamento dos reservatórios de água utilizados nas várias alternativas}

Utilizou-se um reservatório de concreto padrão, cujos detalhes são mostrados na Figura 3:, com custos determinados por meio do SINAPI, na figura 4.

Para o caso dos blocos já existentes, procurou-se utilizar apenas os reservatórios existentes, evitando a construção de novos, por motivos estruturais, particularmente em relação à fundação. A possibilidade de construir reservatórios aparentes no subsolo também foi evitada, devido à redução do número de vagas para veículos.

Esses reservatórios existentes estão inativos por restrição do item 5.2.4.8 da NBR 5626, que trata do risco de contaminação da água potável por materiais provenientes do solo.

Figura 3: Vista em planta do reservatório utilizado

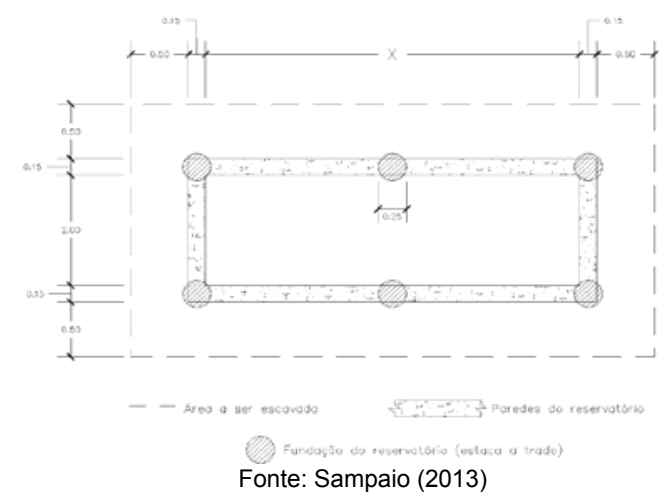

Figura 4: Gráfico do custo do reservatório utilizado em função do seu volume

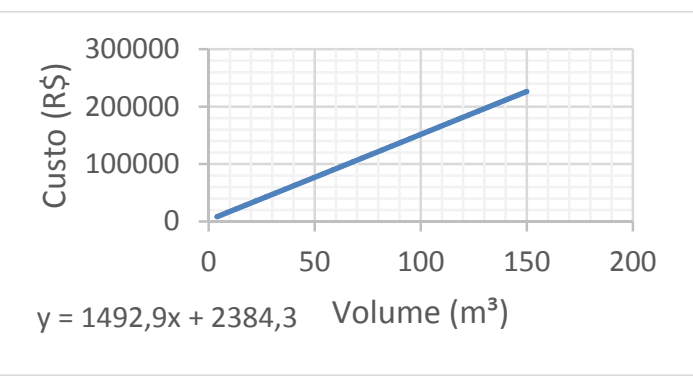

6.8. Descrição e detalhamento da alternativa de implantação de aproveitamento de água da chuva

Utilizaram-se dados da estação meteorológica de Brasília 83377, com dados iniciais desde 1961 (INMET, 2015), com 19.404 dias e o coeficiente de escoamento superficial de 0,8. A área de captação e a demanda foram definidas através da tipologia adotada, de tal forma que se utilizou máxima área de cobertura e a demanda média anual estimada. Foi considerada a necessidade de descarte das águas 
iniciais, totalizando $2 \mathrm{~mm}$ de perda. Utilizou-se o método de simulação diária, calculando a confiabilidade diária dos volumes armazenados através da equação 1 e a escolha final feita através da confiabilidade maior que $98 \%$ e menor projeção ocupada.

Confiab $=\frac{\mathrm{Nr} \text { dias consumo atendido }}{19.404}$

Um aspecto relativo à climatologia de Brasília é que, analisando todas as precipitações diárias dos 19.404 dias da série histórica, apenas $16,7 \%$ dos dias de consumo foram atendidos pela água de chuva do mesmo dia. O restante, foi atendido através do armazenamento da água dos dias anteriores. Isso implicou num aumento do tamanho do reservatório e encareceu o processo.

A concepção do aproveitamento da água de chuva era que toda água da chuva que caísse na cobertura fosse captada, o volume necessário passasse por um tratamento na ETAP (Estação de Tratamento de Águas Pluviais) e, após isso, fosse armazenada no reservatório inferior. De acordo com a necessidade de consumo do reservatório superior conjugado de água de reúso e água pluvial, essa água pluvial deve ser bombeada através de sistema automatizado. As especificações e gastos operacionais da ETAP estão presentes na Tabela 6, considerando o seu uso pleno, desprezando o tempo ocioso. Essa ETAP é composta por filtro grosseiros, finos e bomba dosadora de cloro.

\subsection{Descrição e detalhamento da alternativa de implantação de reúso de água com água cinza clara}

O consumo dos aparelhos que podem ser usados com água de reúso é inferior à produção de água cinza. Com isso, poderia haver um desperdício de água cinza. Portanto, para evitar odores devido à decomposição da matéria orgânica, foi considerado o menor reservatório possível. Foi adotado um reservatório com capacidade para atender à demanda de consumo de água cinza por um período de 24 horas, conforme dados da Tabela 7: Assim, optou-se por tratar somente o volume de água necessária ao consumo, extravasando o excedente para rede de esgoto.

Tabela 6: Dados da ETAP para uso pleno

\begin{tabular}{cc}
\hline Discriminação do dado & Valor \\
\hline Preço $(\mathrm{R} \$)$ & $9.465,00$ \\
Vazão $(\mathrm{L} / \mathrm{h})$ & 2.500 \\
Área ocupada $\left(\mathrm{m}^{2}\right)$ & 1 \\
Consumo de energia $(\mathrm{kwh})$ & 2 \\
Mão de obra para instalação (h/mês) & 45 \\
Consumo de Cloro (kg/mês) & 1,44 \\
Quantidade de areia necessária (kg/mês) & 5,83 \\
Consumo de Carvão ativado (kg/mês) & 5 \\
Custo manutenção (R\$/mês) & 509,65 \\
\hline
\end{tabular}

Tabela 7: Comparação entre a demanda de água e a geração de água de reúso

\begin{tabular}{cccc}
\hline Aparelho & $\begin{array}{c}\text { \% } \\
\text { Consumo }\end{array}$ & Aparelho & $\begin{array}{c}\% \\
\text { Geração }\end{array}$ \\
\hline Bacia Sanitária & 15,3 & Chuveiro & 23,0 \\
Jardim & 1,05 & Tanque & 9,4 \\
Limpeza áreas & 3,15 & $\begin{array}{c}\text { Máquina } \\
\text { de lavar } \\
\text { comuns }\end{array}$ & 21,4 \\
& \multicolumn{3}{r}{$\begin{array}{c}\text { roupa } \\
\text { Lavatório }\end{array}$} \\
\hline
\end{tabular}




\begin{tabular}{cccc}
\hline Total & 19,5 & Total & 62,9 \\
\hline Fonte: Valores em percentuais de Sant'Ana et al. (2013)
\end{tabular}

Foi considerado que seria utilizado um sistema chamado de ETAC (Estação de Tratamento para Água cinza), sendo de fácil instalação e centralizado numa única empresa, com a finalidade de evitar gastos com a coordenação e gestão do processo de instalação. Os dados considerados para a ETAC considerada no presente estudo, com especificações e custos operacionais estão na Tabela 8:, considerando o uso pleno da mesma, desprezando o tempo ocioso. Esses dados foram obtidos por pesquisa de mercado. A ETAC em questão utiliza processos de coagulação, floculação, sedimentação e desinfecção

Tabela 8: Dados da ETAC considerada neste estudo para uso pleno

\begin{tabular}{cc}
\hline Discriminação do dado & Valor do dado \\
\hline Preço $(\mathrm{R} \$)$ & 32.500 \\
Vazão $(\mathrm{L} / \mathrm{h})$ & 1.000 \\
Área $\left(\mathrm{m}^{2}\right)$ & 6 \\
Consumo $(\mathrm{kwh})$ & 4 \\
Produção de lodo $\left(\mathrm{g} / \mathrm{m}^{3}\right)$ & 300 \\
Mão de obra $(\mathrm{h} / \mathrm{mês})$ & 90 \\
Cloro $(\mathrm{kg} / \mathrm{mês})$ & 1,8 \\
Areia $(\mathrm{kg} / \mathrm{mês})$ & 25 \\
Carvão ativado $(\mathrm{kg} / \mathrm{mês})$ & 15 \\
Sulfato de alumínio $(\mathrm{kg} / \mathrm{mês})$ & 10,8 \\
Custo manutenção $(\mathrm{R} \$ / \mathrm{mês})$ & 509,65
\end{tabular}

Para o sistema de reúso de água com água cinza, foi dimensionado um reservatório que atendesse o balanço hídrico entre os aparelhos consumidores e geradores. Foi estabelecido que, durante onze horas por dia, aproximadamente, a produção de água negras é superior em volume, além de ter um pico de diferença da ordem de $3 \mathrm{~L} / \mathrm{hab} / \mathrm{dia}$.

\subsection{Descrição e detalhamento dos custos utilizados na análise}

Observando-se as características da edificação tipo em questão e os custos unitários obtidos em pesquisas em licitações, foram consolidados os dados contidos na Tabela 9. Nessa Tabela é possível visualizar o custo por cômodo e verificar o custo total da reforma das áreas molhadas do apartamento do edifício modelo. Essa reforma é caracterizada pela modernização das instalações sem objetivar a implantação de qualquer alternativa de conservação de água. Contudo, para a maioria das alternativas, conforme é citado na metodologia, fazem-se necessárias tais adequações por serem blocos antigos, da década de 60. Para o edifício modelo seriam gastos $R \$ 4.098 .031,36$, o que contabiliza $R \$ 85.375,65$ por apartamento.

Tabela 9: Custo de reforma das áreas molhadas dos apartamentos na edificação tipo

\begin{tabular}{cccc}
\hline Local & $\begin{array}{c}\text { Custo } \\
\left(\begin{array}{c}\text { Set } \mathbf{2 0 1 6}) \\
\mathbf{R} \mathbf{\$} / \mathbf{m}^{\mathbf{2}}\end{array}\right.\end{array}$ & $\begin{array}{c}\text { Área (m2) } \\
\text { da edificação modelo }\end{array}$ & Subtotal (R\$) \\
\hline banheiro social & 1989,13 & 5,07 & $10.084,89$ \\
cozinha e área de serviço & 1544,80 & 31,02 & $47.919,7$ \\
banheiro de serviço / lavabo & 5271,14 & 1,44 & $7.590,442$ \\
suíte & 3984,78 & 4,25 & $16.935,32$ \\
barrilete & --- & ---- & $54.901,25$ \\
esgoto do subsolo & --- & --- & $81.673,21$ \\
\hline
\end{tabular}

\section{Resultados}

\subsection{Cálculo das vazões de demanda de água para uso nas alternativas}

As medidas incrementais necessitarão das demandas de água e suas fontes. Essa relação pode gerar diversas alternativas. 
Optou-se, inicialmente, pela seleção de todos os aparelhos de consumo da Tabela 7: (demanda e geração dos aparelhos), seguindo duas premissas: (1) utilizar o mínimo de água potável nos pontos que forem atendidos por fonte de água não potável (preferencialmente zero); e (2) maximizar o uso de água cinza/pluviais (extravasar o menor volume).

\section{A 7.2. Balanço hídrico para as alternativas de reúso de água com água cinza clara}

Observando-se os valores da Tabela 7: (demanda e geração dos aparelhos), e seguindo as mesmas premissas da demanda, obteve-se a Tabela 11:, relativa às fontes de água. A soma da coluna "volume" refere-se ao volume produzido pelos equipamentos da opção em questão, em metros cúbicos, utilizando os dados (consumo mensal) do edifício modelo. As escolhas preferenciais iniciais estão em destaque (em negrito). Essa preferência ocorre devido à compatibilização com a escolha preferencial da demanda (Tabela 10).

resume as possibilidades de demanda de água estudadas, utilizando os consumos percentuais da Figura 1, combinados com os valores de consumo da edificação modelo. A escolha preferencial inicial está em destaque (em negrito). Essa preferência ocorreu devido à maior possibilidade de consumo de água atendendo a todas as premissas já citadas.

Tabela 10: Alternativa de demanda de água dos equipamentos passíveis de uso com água não potável

\begin{tabular}{ccccc}
\hline Opção & $\begin{array}{c}\text { Bacia } \\
\text { Sanitária } \\
\left(\mathrm{m}^{3} / \mathrm{mês}\right)\end{array}$ & $\begin{array}{c}\text { Jardim } \\
\left(\mathrm{m}^{3} / \mathrm{mês}\right)\end{array}$ & $\begin{array}{c}\text { Limpeza } \\
\left(\mathrm{m}^{3} / \mathrm{mês}\right)\end{array}$ & $\begin{array}{c}\text { Volume } \\
\left(\mathrm{m}^{3} / \mathrm{mês}\right)\end{array}$ \\
\hline 1 & 133 & 10 & 28 & 170 \\
2 & 133 & 0 & 28 & 161 \\
3 & 133 & 10 & 0 & 142 \\
4 & 133 & 0 & 0 & 133 \\
5 & 0 & 0 & 0 & 37 \\
6 & 0 & 0 & 0 & 27 \\
7 & 0 & 0 & 0 & 9 \\
\hline
\end{tabular}

\subsection{Balanço hídrico para as alternativas de reúso de água com água cinza clara}

Observando-se os valores da Tabela 7: (demanda e geração dos aparelhos), e seguindo as mesmas premissas da demanda, obteve-se a Tabela 11:, relativa às fontes de água. A soma da coluna "volume" refere-se ao volume produzido pelos equipamentos da opção em questão, em metros cúbicos, utilizando os dados (consumo mensal) do edifício modelo. As escolhas preferenciais iniciais estão em destaque (em negrito). Essa preferência ocorre devido à compatibilização com a escolha preferencial da demanda (Tabela 10).

Tabela 11: Equipamentos que podem ser utilizados com fontes de água não potável.

\begin{tabular}{cccccc}
\hline & $\begin{array}{c}\text { Chuveiro } \\
\left(\mathrm{m}^{3} / \mathrm{mês}\right)\end{array}$ & $\begin{array}{c}\text { Tanque } \\
\left(\mathrm{m}^{3} / \mathrm{mês}\right)\end{array}$ & $\begin{array}{c}\text { Máquina de } \\
\text { Lavar Roupa } \\
\left(\mathrm{m}^{3} / \mathrm{mês}\right)\end{array}$ & $\begin{array}{c}\text { Lavatório } \\
\left(\mathrm{m}^{3} / \mathrm{mês}\right)\end{array}$ & $\begin{array}{c}\text { Volume } \\
\left(\mathrm{m}^{3} / \mathrm{mês}\right)\end{array}$ \\
\hline $\mathbf{1}$ & 200 & 82 & 186 & 79 & 547 \\
$\mathbf{2}$ & 200 & 82 & 186 & 0 & 468 \\
$\mathbf{3}$ & 200 & 0 & 186 & 79 & 465 \\
$\mathbf{4}$ & 200 & 0 & 186 & 0 & 386 \\
$\mathbf{5}$ & 200 & 82 & 0 & 79 & 361 \\
$\mathbf{6}$ & 0 & 82 & 186 & 79 & 347 \\
$\mathbf{7}$ & 200 & 82 & 0 & 0 & 281 \\
$\mathbf{8}$ & 200 & 0 & 0 & 79 & 279 \\
$\mathbf{9}$ & 0 & 82 & 186 & 0 & 267 \\
$\mathbf{1 0}$ & 0 & 0 & 186 & 79 & 265 \\
$\mathbf{1 1}$ & 200 & 0 & 0 & 0 & 200 \\
$\mathbf{1 2}$ & $\mathbf{0}$ & $\mathbf{0}$ & $\mathbf{1 8 6}$ & $\mathbf{0}$ & $\mathbf{1 8 6}$ \\
$\mathbf{1 3}$ & $\mathbf{0}$ & $\mathbf{8 2}$ & $\mathbf{0}$ & $\mathbf{7 9}$ & $\mathbf{1 6 0}$ \\
$\mathbf{1 4}$ & $\mathbf{0}$ & $\mathbf{8 2}$ & $\mathbf{0}$ & $\mathbf{0}$ & $\mathbf{8 1}$ \\
$\mathbf{1 5}$ & $\mathbf{0}$ & $\mathbf{0}$ & $\mathbf{0}$ & $\mathbf{7 9}$ & $\mathbf{7 9}$ \\
\hline
\end{tabular}

Utilizando as premissas já expostas, e considerando que a demanda máxima de água cinza foi de 
$170 \mathrm{~m}^{3} / \mathrm{mês}$ (da Tabela 10), podem-se descartar todas as opções de oferta com maior volume. Portanto, pela comparação do volume da geração de água cinza para reúso, foram eliminadas as alternativas de ofertas de 1 a 11 (tabela 11). A alternativa 12 manteve-se no limiar, portanto, por cautela, evitou-se a sua exclusão imediata.

Já em relação à demanda, a menor produção de água cinza para reúso foi de $79 \mathrm{~m}^{3} / \mathrm{mês}$. Com isso, foram eliminadas as alternativas de demanda 5 a 7 (Tabela 10).

Ao final restaram 16 alternativas de combinação demanda-oferta, que foram consolidadas na Tabela 12 com seus respectivos saldos de volume de água. As colunas de opções de demanda e oferta foram selecionadas a partir dos critérios e análises já expostos, Tabela 10 e Tabela 11:, respectivamente. A coluna de "saldo" foi calculada a partir da diferença dos valores das opções obtidas nas tabelas em questão.

Tabela 12: Combinações de alternativas e seus respectivos saldos.

\begin{tabular}{ccc}
\hline Demanda (opção) & Fonte (opção) & Saldo $\left(\mathrm{m}^{3}\right)$ \\
\hline 1 & 15 & -91 \\
1 & 14 & -88 \\
2 & 15 & -81 \\
2 & 14 & -79 \\
3 & 15 & -63 \\
3 & 14 & -60 \\
4 & 15 & -53 \\
4 & 14 & -51 \\
1 & 13 & -9 \\
2 & 13 & 0 \\
1 & 12 & 15 \\
3 & 13 & 18 \\
2 & 12 & 25 \\
4 & 13 & 27 \\
3 & 12 & 43 \\
4 & 12 & 53 \\
\hline
\end{tabular}

Diante da análise do volume no saldo e das premissas já expostas, a alternativa cuja demanda é 2 e a fonte é 13 está praticamente no equilíbrio desejado. Os candidatos mais próximos em valor, através da comparação pelo volume de saldo, foram 1-13 e 1-12. Assim, não foi possível eliminar nenhuma dessas três alternativas.

Portanto, as alternativas selecionadas foram o uso da demanda pelas opções 1 (Bacia + Limpeza + Jardim) e 2 (Bacia + Limpeza) e com fontes nas opções 12 (máquina de lavar roupa) e 13 (Tanque + Lavatório).

Para o cálculo do volume do reservatório, considerou-se o caso máximo de consumo, que foi $170 \mathrm{~m}^{3} /$ dia, e a estimativa de 12 horas por dia de produção de água cinza, teve-se uma vazão de $14,2 \mathrm{~m}^{3} / \mathrm{h}$, que necessitaria de um reservatório de $8 \mathrm{~m}^{3}$ para atender o tempo de contato mínimo. Diante disso, recomenda-se um reservatório inferior de, no mínimo, $8 \mathrm{~m}^{3}$.

\subsection{Balanço hídrico para as alternativas de aproveitamento da água da chuva e cálculo do volume de reservatório necessário}

$\mathrm{O}$ aproveitamento de águas pluviais tem a mesmas características da água de reúso. A única diferença dos dois sistemas entre as categorias foi o reservatório. Com isso, esta seção tratou das duas categorias e apenas diferenciou-as nos aspectos referentes à escolha do reservatório final.

Utilizando o consumo máximo predial de água da chuva que é de $170 \mathrm{~m}^{3} / \mathrm{mês}$ e o mínimo, que é de $9,5 \mathrm{~m}^{3} / \mathrm{mês}$, e aplicando-se os métodos de dimensionamento para reservatórios de água da chuva, foram obtidos os resultados apresentados na Tabela 13: 
Tabela 13: Volume dos reservatórios de água de chuva obtidos com simulação com dados diários

\begin{tabular}{cccc}
\hline Volume $\left(\mathrm{m}^{3}\right)$ & Custo $(\mathrm{R} \$)$ & Projeção da área $\left(\mathrm{m}^{2}\right)$ & Confiabilidade \\
\hline 250 & 375.620 & 1.115 & 99,72 \\
135 & 203.932 & 603 & 98,33 \\
125 & 189.002 & 558 & 97,36 \\
100 & 151.679 & 447 & 93,06 \\
\hline
\end{tabular}

Diante de diversos métodos para dimensionamento do reservatório, foi escolhida a mediana dos mesmos, resultando em $135 \mathrm{~m}^{3}$ totais, sendo $75 \mathrm{~m}^{3}$ a serem construídos, com custo de $\mathrm{R} \$ 114.355,60$. Isso ocorreu devido a existência de um reservatório desativado de $60 \mathrm{~m}^{3}$ que se propõe seja utilizado (no caso de edificação existente).

Não foi possível utilizar a demanda total, referente a bacias sanitárias, irrigação e lavagem de pisos $\left(170 \mathrm{~m}^{3}\right)$ devido à chance de se ter 6 meses (maio a outubro) de déficit de água. Diante dessa escassez de água, verificou-se a possibilidade de atendimento apenas para as bacias sanitárias $\left(133 \mathrm{~m}^{3}\right)$, conforme a Tabela 14: Com isso, pode-se ver que houve maior confiabilidade, correspondendo a $94,4 \%$ ( $\Sigma$ volume chuva/ $\sum$ demanda) e probabilidade de falha em apenas 4 meses (junho, julho, agosto e setembro).

\subsection{Resultado do procedimento de geração de alternativas para análise}

A análise econômica das medidas de redução, através da viabilidade econômica, gerou sete opções com seus respectivos períodos de retorno, conforme é mostrado na

Tabela 15: Algumas dessas medidas de redução de consumo de água não apresentaram um tempo de retorno passível de ser determinado matematicamente pois não demonstraram sua viabilidade econômica (receitas inferiores às despesas) e com isso foram eliminadas. Tal fato ocorreu devido ao baixo fluxo de caixa mensal. Entre as medidas mais rentáveis, surgem os aparelhos economizadores de água.

Tabela 14: Análise da situação com a chuva mensal quando se emprega um reservatório com capacidade de 135 $\mathrm{m}^{3}$ e consumo apenas com bacias sanitárias

\begin{tabular}{ccccccc}
\hline & $\begin{array}{c}\text { Precipitação } \\
(\mathrm{mm})\end{array}$ & $\begin{array}{c}\text { Demanda } \\
\left(\mathrm{m}^{3}\right)\end{array}$ & $\begin{array}{c}\text { Oferta } \\
\left(\mathrm{m}^{3}\right)\end{array}$ & $\begin{array}{c}\text { Reservatório } \\
\mathrm{em} \mathrm{t-1}\left(\mathrm{m}^{3}\right)\end{array}$ & $\begin{array}{c}\text { Reservatório } \\
\mathrm{em} \mathrm{t}\left(\mathrm{m}^{3}\right)\end{array}$ & $\begin{array}{c}\text { Déficit de água } \\
\left(\mathrm{m}^{3}\right)\end{array}$ \\
\hline Jan & 284 & 133 & 257 & 0 & 124 & 0 \\
Fev & 211 & 133 & 191 & 124 & 124 & 0 \\
Mar & 224 & 133 & 202 & 124 & 124 & 0 \\
Abr & 136 & 133 & 123 & 124 & 113 & 0 \\
Mai & 34 & 133 & 31 & 113 & 11 & 0 \\
Jun & 7 & 133 & 6 & 11 & -116 & 116 \\
Jul & 10 & 133 & 9 & 0 & -124 & 124 \\
Ago & 14 & 133 & 13 & 0 & -120 & 120 \\
Set & 49 & 133 & 44 & 0 & -89 & 89 \\
Out & 163 & 133 & 147 & 0 & 14 & 0 \\
Nov & 260 & 133 & 235 & 14 & 116 & 0 \\
Dez & 276 & 133 & 249 & 116 & 116 & 0 \\
\hline
\end{tabular}

Tabela 15: Período de Retorno e custo das medidas de redução de consumo de água

\begin{tabular}{ccc}
\hline Opção de medida de redução de consumo de água & $\begin{array}{c}\text { Tempo de Retorno } \\
\text { (meses) }\end{array}$ & $\begin{array}{c}\text { Custo } \\
\text { (R\$) }\end{array}$ \\
\hline Economizador & 50 & $49.578,20$ \\
Medição individual + economizador & Indeterminado & $169.578,20$ \\
Medição individual & Indeterminado & $120.000,00$ \\
\hline
\end{tabular}

INDETERMINADO: Ocorre quando não há retorno financeiro do empreendimento, apenas há o aumento do défict.

Diante dos resultados da análise econômica das medidas de redução de consumo de água, tendo sido melhor situada nessa análise a utilização de aparelhos economizadores, e das triagens realizadas junto às alternativas, obteve-se a informação sistematizada apresentada na Tabela 16, que contém um resumo da composição das alternativas selecionadas para seguir para a análise multiobjectivo e multicritério. 
Tabela 16: Resumo das alternativas finais

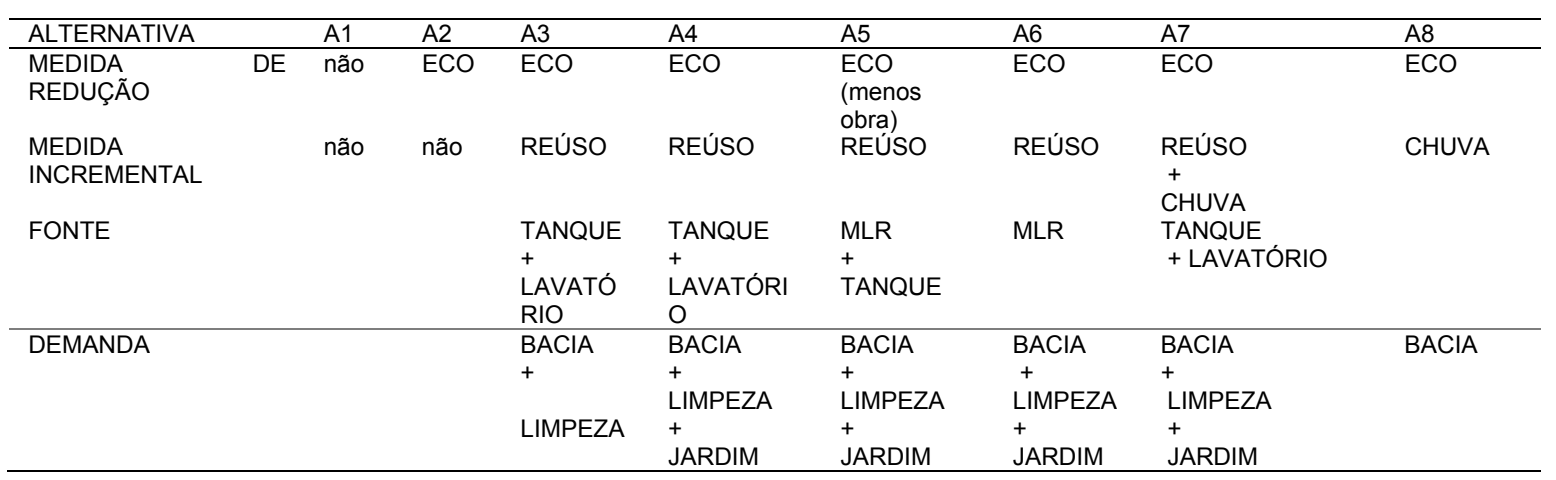

Legenda: ECO- emprego de sistemas economizadores de água; MLR- uso da água da máquina de lavar roupa; TANQUEuso da água oriunda do tanque; LAVATÓRIO- uso de água proveniente do lavatório dos banheiros; BACIA- utilização de água nas bacias sanitárias; LIMPEZA- utilização de água para limpeza em áreas comuns; JARDIM- utilização de água para irrigação dos jardins; CHUVA- utilização de sistema de captação de água da chuva; REÚSO- utilização de sistema de reúso de água cinza;

Diante dos dados já explanados, produziu-se a Tabela 17 com os valores dos desempenhos de cada alternativa segundo os diferentes critérios considerados na análise. Existem diversos valores nulos devido a não existência desses itens em algumas alternativas, tal como coliformes fecais na Alternativa A1

Tabela 17: Matriz de Consequências ("Payoff Matrix")

\begin{tabular}{|c|c|c|c|c|c|c|c|c|}
\hline CRITÉRIOS & A1 & A2 & A3 & A4 & A5 & A6 & A7 & A8 \\
\hline VPL $(R \$)$ & 348.608 & $-0,50$ & -3.673 .936 & -3.688 .869 & $-0,17$ & $-0,01$ & $-0,01$ & $-0,01$ \\
\hline $\begin{array}{c}\text { Custo de } \\
\text { implantação } \\
(R \$)\end{array}$ & 0,00 & $48.566,4$ & $4.179 .097,7$ & $4.179 .097,7$ & $162.739,6$ & $4.179 .097,7$ & $4.302 .914,5$ & $4.270 .414,5$ \\
\hline $\begin{array}{c}\text { Custo de } \\
\text { operação (R\$) }\end{array}$ & $1.644,00$ & 28,72 & $1.415,23$ & $1.415,23$ & $1.415,23$ & $1.415,23$ & $1.835,16$ & 448,64 \\
\hline TR & 1 & 6,47 & 7,39 & 7,39 & 7,18 & 7,39 & 7,39 & 7,39 \\
\hline $\mathrm{DBO}(\mathrm{mg} / \mathrm{L})$ & 0 & 0 & 392 & 392 & 607 & 624 & 224 & 7 \\
\hline SST (mg/L) & 0 & 0 & 187 & 187 & 210 & 206 & 130 & 56 \\
\hline $\begin{array}{c}\text { CF (NMP/100 } \\
m L)\end{array}$ & 0 & 0 & 2.230 & 2.230 & 11.422 & 16.000 & 1.267 & 35 \\
\hline $\begin{array}{l}\text { Volume de } \\
\text { água a ser } \\
\text { reduzido do } \\
\text { consumo }\left(\mathrm{m}^{3}\right)\end{array}$ & 0 & 174 & 335 & 326 & 344 & 344 & 344 & 283 \\
\hline $\begin{array}{c}\text { Volume de } \\
\text { água } \\
\text { complementar } \\
\left(\mathrm{m}^{3}\right) \\
\text { Volume de }\end{array}$ & 170 & 0 & 0 & 9 & 0 & 0 & 0 & 37 \\
\hline $\begin{array}{c}\text { água } \\
\text { desperdiçado } \\
\left(\mathrm{m}^{3}\right)\end{array}$ & 348 & 0 & 0 & 0 & 97,9 & 16 & 65 & 17 \\
\hline Lodo (kg/ano) & 0 & 0 & 580 & 580 & 612 & 612 & 333 & 65 \\
\hline $\begin{array}{c}\text { Risco a saúde } \\
\text { Risco anual }\end{array}$ & 7,39 & 7,39 & 6,74 & 6,74 & 3,79 & 4,17 & 7,01 & 7,37 \\
\hline $\begin{array}{l}\text { da falta de } \\
\text { água }(\%)\end{array}$ & 0 & 0 & 0 & 6 & 0 & 0 & 0 & 39 \\
\hline $\begin{array}{l}\text { Interferência } \\
\text { ao morador }\end{array}$ & 0 & 3 & 9 & 9 & 5 & 7 & 10 & 1 \\
\hline $\begin{array}{l}\text { Consumo de } \\
\text { energia (kWh) }\end{array}$ & 0 & 0 & 4 & 4 & 4 & 4 & 6 & 2 \\
\hline $\begin{array}{c}\text { Área ocupada } \\
\qquad\left(\mathrm{m}^{2}\right)\end{array}$ & 0 & 0 & 6 & 6 & 6 & 6 & 7 & 1 \\
\hline $\begin{array}{l}\text { Complexidade } \\
\text { de instalação }\end{array}$ & 0 & 1 & 8 & 8 & 9 & 9 & 10 & 4 \\
\hline
\end{tabular}


Da aplicação dos métodos multiobjetivo e multicritério TOPSIS e ELECTRE III, apresentados anteriormente, obtiveram-se os resultados contidos na Tabela 18:. Nessa tabela aparece o valor do coeficiente de similaridade (Ck) do Método TOPSIS, para o qual a alternativa é tanto melhor quanto maior for o seu valor - quanto mais próximo de 1 for $\mathrm{Ck}$, melhor é a alternativa. Esse resultado foi obtido através da métrica 1ou seja, priorizando as alternativas com melhor utilidade de grupo. Já no método ELECTRE III, foram utilizados os parâmetros de preferência, indiferença e veto conforme tabela 19.

Tabela 18: Resultados da aplicação dos métodos TOPSIS e ELECTRE III-III na avaliação das alternativas de conservação predial de água consideradas (ranking das alternativas)

\begin{tabular}{ccccc}
\hline ALTERNATIVAS & \multicolumn{2}{c}{ TOPSIS } & ELECTRE III & FINAL \\
& Ck & ORDEM & $\begin{array}{c}\text { ORDEM } \\
\text { ORDEM }\end{array}$ \\
\hline A1 & 0,78 & 2 & 2 & 2 \\
A2 & 0,91 & 1 & 1 & 1 \\
A3 & 0,44 & 5 & 4 & 4 \\
A4 & 0,43 & 6 & 5 & 6 \\
A5 & 0,41 & 7 & 3 & 5 \\
A6 & 0,34 & 8 & 5 & 7 \\
A7 & 0,48 & 4 & 2 & 3 \\
A8 & 0,71 & 3 & 3 & 3
\end{tabular}

Tabela 19- Coeficientes do método ELECTRE

\begin{tabular}{lllc}
\hline Critério de julgamento & $\mathrm{q}$ & $\mathrm{p}$ & $\mathrm{V}$ \\
\hline ECONÔMICO & & & \\
\hline VPL & 10.000 & 30.000 & 210.000 \\
\hline Custo de implantação & 10.000 & 30.000 & 210.000 \\
\hline Custo de operação & 300 & 800 & 1.000 \\
\hline Tempo de retorno & 0,10 & 0,20 & 1,00 \\
\hline QUALIDADE DE ÁGUA & & & 300 \\
\hline DBO & 10 & 100 & 150 \\
\hline SST & 50 & 100 & 5.250 \\
\hline CF & 250 & 750 & 1.050 \\
\hline AMBIENTAL & & & 1.050 \\
\hline Volume de água reduzido do consumo final & 50 & 150 & 1.050 \\
\hline Volume de água complementar & 50 & 150 & 400 \\
\hline Volume de água desperdiçado & 50 & 150 & 1.00 \\
\hline Quantidade de lodo & 40 & 100 & 36 \\
\hline SOCIAL & & & 9 \\
\hline Risco a saúde & 0.2 & 0.3 & 1.050 \\
\hline Risco anual de falta de água & 3 & 9 & 315 \\
\hline Interferência ao morador & 2 & 6 & 9 \\
\hline TÉCNICO & & & 150 \\
\hline Consumo de energia & 50 & 45 & 6 \\
\hline Área ocupada pelo sistema & 15 & 2 & \\
\hline Complexidade do sistema & & 6 & \\
\hline
\end{tabular}

Após análises isoladas dos dois métodos, pôde-se realizar a análise global, produzindo-se a última coluna através da mediana dos valores de ordem.

\section{Conclusões}

Diante desses resultados finais mostrados na Tabela 18, notou-se que a Alternativa A2 (uso apenas de economizadores) foi destaque positivo em todas as aplicações dos métodos, mostrando sua robustez e performance. Tal fato ratifica os princípios de conservação de água propostos por WUCB (1999). Cabe ressaltar que esta alternativa está embutida nas outras, sendo, portanto, apenas referência.

$\mathrm{Na}$ segunda posição do ranking apresentou-se a Alternativa A1 (não tomar qualquer atitude, não realizar conservação predial de água). Seu destaque foi devido ao uso de apenas água potável para todas as atividades, o que lhe conferiu boas notas no objetivo de qualidade de água e no critério de risco à saúde, mascarando a priorização do uso racional de água, podendo gerar a interpretação do uso inadequado e desordenado como satisfatório. Cabe ressaltar que essa alternativa não faz parte do 
rol de alternativas de uso racional e sim como uma testemunha e serve para demonstrar que há algo errado na compreensão do problema pela sociedade, o que precisa ser modificado, e que são necessários mais incentivos governamentais para alavancar as medidas de conservação de água.

$\mathrm{Na}$ terceira posição no ranking apareceu a Alternativa A8 (utilizar a água da chuva nas bacias sanitárias) empatada com a Alternativa A7 (água da chuva e reúso de água das fontes do tanque e do lavatório e demanda das bacias, limpeza predial e jardins).

Ambas com dados econômicos similares, porém a Alternativa A7 apresenta excesso de volume de água captado por medidas incrementais e uma qualidade de água inferior a A8.

A última posição foi ocupada pela a Alternativa A6 (reúso com fonte da máquina de lavar roupa com demanda das bacias, limpeza predial e jardins). Tal fato acontece pela alta importância relativa do objetivo qualidade de água.

Diante de todo o exposto, e com base nos pesos e critérios apresentados, considera-se viável a adoção de economizadores e implantação do sistema de água da chuva nos casos de reformas prediais. Apesar de ter sido considerada a existência de um reservatório desativado, sua existência tem influência apenas nos subobjetivos econômicos. Tal fato não modifica as classificações devido à baixa diferença financeira oriunda desse reservatório (menor que cem mil reais, $2 \%$ do custo de implantação).

O surgimento da ALTERNATIVA 1 entre as três primeiras posições, independentemente do método, sugere que não existe incentivo para a adoção de medidas relacionadas ao reúso de água e ao aproveitamento de água de chuva por parte tanto do Governo e como das concessionárias. De fato, é possível constatar que estas últimas evitam o tema e provocam discussões acerca dos riscos relacionados à qualidade da água, no intuito de evitar a adoção de incentivos, muito provavelmente devido à crença de que haverá diminuição de lucros e possíveis problemas (não comprovados) de diminuição da relação água e esgoto nas redes coletoras. Com isso, sugere-se simular nesse modelo diversas ações de políticas públicas para analisar e testar a eficiência de cada alternativa.

\section{REFERÊNCIAS BIBLIOGRÁFICAS}

ASSOCIAÇÃO BRASILEIRA DE NORMAS TÉCNICAS (ABNT). NBR 15.527: Água da Chuva Aproveitamento de coberturas em áreas urbanas para fins não potáveis-Requisitos. Rio de Janeiro,2007.

ASSOCIAÇÃO BRASILEIRA DE NORMAS TÉCNICAS (ABNT). NBR 15.575: Desempenho de edificações habitacionais- Requisitos. Rio de Janeiro,2013.

Atlas Brasil. Abastecimento urbano de água: panorama nacional. Brasília. 2010. Agência Nacional de Águas; Engecorps/Cobrape.

BARRETO, D. Water conservation and the monitoring of sanitary appliances. 1990. $196 \mathrm{f}$. Dissertação (Mestrado em Building Services Engineering) - , Heriot Watt University Edinburgh, Edinburgh, 1990

BAZZARELLA, B. B. Caracterização e aproveitamento de água cinza para uso não-potável em edificações. Vitória-ES, 2005. 65p.

BRASIL. Ministério do Meio Ambiente. Conselho Nacional de Recursos Hídricos. Resolução No 54 de 28 de novembro de 2005. Estabelece modalidades, diretrizes e critérios gerais para a prática de reúso direto não potável e dá outras providências.

CAMPOS, M. A. S. Aproveitamento de água pluvial em edifícios residenciais multifamilares na cidade 
de São Carlos. Dissertação de Mestrado em Construção Civil. São Carlos: UFSCar, 2004. Departamento de Engenharia Civil. 157 p.

CHAIN, R. R.; FIGUEIRA NETTO, C. A. M.; MESSUTI, E. Sistema de Reaproveitamento de Água para Edificações. Rio de Janeiro,1999. Trabalho V-053. Anais do $20^{\circ}$ Congresso Brasileiro de Engenharia Sanitária e Ambiental.

COMPANHIA DE SANEAMENTO AMBIENTAL DO DISTRITO FEDERAL (CAESB). Apresentação área comercial, 2012. Disponível em: <http://www.orcamentofederal.gov.br/

eficiencia-do-gasto/Apresentacao_Caesb_12042012.pdf>. Acesso em: 09 jun. 2012.

GONÇALVES, O. M.; ILHA, M. S. O.; AMORIM, S. Indicadores de uso racional de água em escolas públicas de ensino fundamental e médio. São Paulo, 2004. Relatório de pesquisa desenvolvida dentro do edital CT-HIDRO do CNPq.

GRISOLIA, P. Z. Gestão da demanda para uso racional da água (URA). São Paulo, 2015. Manual de sustentabilidade Condominial -SECOVISP.

HAFNER, A. V. Conservação e reúso de água em edificações - experiências nacionais e internacionais. Rio de Janeiro: UFRJ, 2007. Dissertação de Mestrado em Engenharia Civil.

HESPANHOL, I.; GONÇALVES, O. M. (Coordenadores). Conservação e Reúso de Água - Manual de Orientações para o Setor Industrial, Vol. 1, 2004.

Instituto Brasileiro de Geografia e Estatística. Censo Demográfico 2000. Disponível em:< http://www.ibge.gov.br>. Acesso em: 10 jan. 2016.

LAZAROVA, V.; HILLS, S.; BIRKS, R. Using recycled water for non-potable, urban uses: a review with particular reference to toilet flushing. London, 2003.Water Science and Technology: Water upply, , v. 3, n. $4 . ;$ p. $69-77$.

LOBATO, M.B. (2005). Sistema de hierarquização de ações de conservação da água em edificações com aplicação do método ELECTRE III III. Campinas: UNICAMP, 2005. Dissertação de Mestrado. Programa de Pós-Graduação em Engenharia Civil Arquitetura e Urbanismo. 260p.

MIELI, J. Reúso de água domiciliar. Niterói: UFF, 2001. Dissertação Mestrado Programa de PósGraduação em Engenharia Civil, Área de Concentração: Produção Civil.

MURÇA, M. C. R. Aproveitamento de águas pluviais em instalações militares do Comando da Aeronáutica: aplicação ao caso do PAMA-GL. São José dos Campos: ITA, 2011. Trabalho de graduação Engenharia Civil, Divisão de Engenharia Civil. 138p.

NIRENBERG, L.P; REIS, R.P.A. Avaliação do desempenho de sistema de reúso de água de uma edificação unifamiliar em Goiânia/GO. Goiânia, 2010. Revista Eletrônica de Engenharia Civil, v. 1, 1$13 p$.

RAPOPORT, B. Águas cinzas: caracterização, avaliação financeira e tratamento para reúso domiciliar e condominial. Rio de Janeiro: ENSP, 2004. Dissertação de mestrado. 119 p.

REBOUÇAS, A. C.; BRAGA, B.; TUNDISI, J. G. (Org.). Águas doces no Brasil. $2^{a}$.ed. São Paulo: Escrituras Editora, 2002. 703p.

ROCHA, A. L. Perfil de consumo de água de uma habitação unifamiliar. In: CONGRESSO BRASILEIRO DE ENGENHARIA SANITÁRIA E AMBIENTAL, 20., 1999. Rio de Janeiro. Anais... Rio de Janeiro: ABES, 1999. 
SAMPAIO, F. V. Análise da viabilidade de implantação e pré-dimensionamento de sistemas de aproveitamento de água pluvial em centros urbanos. Brasília: UnB,2013. Dissertação de Mestrado em Tecnologia Ambiental e Recursos Hídricos, Publicação PTARH.DM 154/2013. Departamento de Engenharia Civil e Ambiental. 165p.

SANT'ANA, D.; BOEGER, L.; VILELA, L. Aproveitamento de águas pluviais e o reúso de águas cinzas em edifícios residenciais de Brasília - Parte 1: redução no consumo de água. Brasília: Paranoá, Brasília, no 10, 2013. p. 77-84.

SANT'ANA, D.; BOEGER, L.; VILELA, L. Aproveitamento de águas pluviais e o reúso de águas cinzas em edifícios residenciais de Brasília - Parte 2: viabilidade técnica e econômica. Brasília: Paranoá, Brasília, n 10, 2013. p. 85-93.

SANTOS. D. C.; LOBATO. M.B.; VOLPI. N.M.P.; BORGES.L.Z. Hierarquização de medidas de conservação de água em edificações residenciais com o auxílio de análise de multicritério. Porto Alegre, 2006. Ambiente Construído, v. 6, n. 1, p. 31-47.

SILVA, S. R. S. Avaliação do sistema de medição individualizada de água em prédios populares situados na cidade de Salvador-Bahia. Salvador: UFBA, 2010. Dissertação (Mestrado Profissional em Gerenciamento e Tecnologia Ambiental no Processo Produtivo). Disponível em: $<$ https://repositorio.ufba.br/ri/handle/ri/9585>. Acesso em: out. 2015.

TECHMETRIA. Sistema de medição individual. Perguntas e Respostas frequentes. Disponível em: <http://www.techmetria.com.br/site/faq.php>. Acesso em: 22 ago. 2016.

U.S. Environmental Protection Agency (EPA). Guidelines for Water Reuse, 1992.

WUCB. A water conservation guide for commercial, institutional and industrial users. New Mexico: Ed. Water Use and Conservation Bureau,1999. 